\section{Hak Sung Kim, Seok Won Kim}

Department of Neurosurgery, Chosun University College of Medicine, Gwangju, Korea

\section{Corresponding Author:}

Seok Won Kim

Department of Neurosurgery,

Chosun University Hospital,

Chosun University College of

Medicine, 309 Pilmun-daero,

Dong-gu, Gwangju 61452, Korea

Tel: +82-62-220-3126

Fax: +82-62-227-4575

E-mail: chosunns@chosun.ac.kr

Received: December 13, 2016

Revised: April 21, 2017

Accepted: August 8, 2017
Copyright $(\subset 2017$ by The Korean Spinal Neurosurgery Society

This is an open access article distributed under the terms of the Creative Commons Attribution Non-Commercial License (http://creativecommons.org/licenses/by$\mathrm{nc} / 4.0 /$ ) which permits unrestricted noncommercial use, distribution, and reproduction in any medium, provided the original work is properly cited.

\title{
Hemorrhagic Lumbar Synovial Cyst after Microscopic Discectomy
}

Intraspinal synovial cysts are rare but they are being documented with increasing frequency due to improvements in radiological imaging. However, hemorrhage into synovial cysts is uncommon, and affected patients may present with acute onset radiculopathy. This type of hemorrhage is known to result from rupture of fragile neoangiogenic vessels in the cyst wall, due to a traumatic event or anticoagulant therapy. Here, the authors present a rare case of hemorrhagic lumbar synovial cyst caused by spinal instability after microscopic discectomy. To the best of the authors' knowledge, this is the first report of hemorrhagic lumbar synovial cyst caused by spinal instability following microscopic discectomy in the absence of a traumatic event or anticoagulant therapy. We discuss the pathophysiological mechanism of this uncommon entity and provide a review of the literature.

Key Words: Lumbar, Cyst, Discectomy

\section{INTRODUCTION}

Symptomatic hemorrhagic lumbar facet cyst is a rare condition, and few cases have been reported $^{6}$. Although its precise cause and pathogenesis are debatable, it is believed that bleeding into a synovial cyst results in acute increases in pain and radicular symptoms, including neurological deficits ${ }^{1,8}$. In most cases, a hemorrhagic presentation could be caused by anticoagulation therapy, trauma, or vascular anomaly ${ }^{4}$. Here, we present a case of hemorrhagic lumbar facet cyst caused by spinal instability after microscopic discectomy in the absence of such predisposing conditions.

\section{CASE REPORT}

A 56-year-old woman experienced disabling back and left leg pain for 3 months before surgery. Radiological studies, including simple radiographs with flexion and extension views and magnetic resonance (MR) images revealed lumbar disc herniation at the L4-5 level without instability (Fig. 1). She underwent L4 -5 microscopic discectomy following bilateral lami- notomy to reduce the extent of laminectomy. After surgery, her presenting symptoms were much improved and she was discharged without pain. However, at 6 months after surgery, the patient complained of sudden onset pain radiating to left thigh and numbness of the left leg. A neurologic examination conducted at the time revealed no neurologic deficits, and bowel and bladder function were normal. However, the straight leg raising test elicited pain the left leg at $45^{\circ}$, which was exacerbated by ankle dorsiflexion. Under a preliminary diagnosis of recurrent disc herniation, simple radiographs and MR images were obtained. Dynamic flexion and extension views revealed progression of instability at the L4-5 level and MR images showed the presence of a cystic formation in the left L4-5 facet joint with arthritis compressing the left $\mathrm{L} 5$ root and dural sac. In addition, MRI displayed a hypointense abnormality on T1-weighted images and a corresponding hyperintense abnormality on T2-weighted images, which was consistent with hemorrhage (Fig. 2). Surgical excision was performed 3 days after readmission with posterior lumbar interbody fusion using pedicle screws due to the subsequent instability. The lesion adhered slightly to dura mater, and contained old coagulated darkbrown blood. Histologic examination of the surgical specimen revealed a cystic wall composed of fibrous connective tissue containing an old hematoma with hemosiderin deposits (Fig. 3). After surgery, her symptoms immediately faded and at last follow-up (9 months after revision surgery), no symptom recurrence or neurologic aggravation was evident.

\section{DISCUSSION}

Cysts around the facet joints are called juxtafacet cysts and include synovial and ganglion 

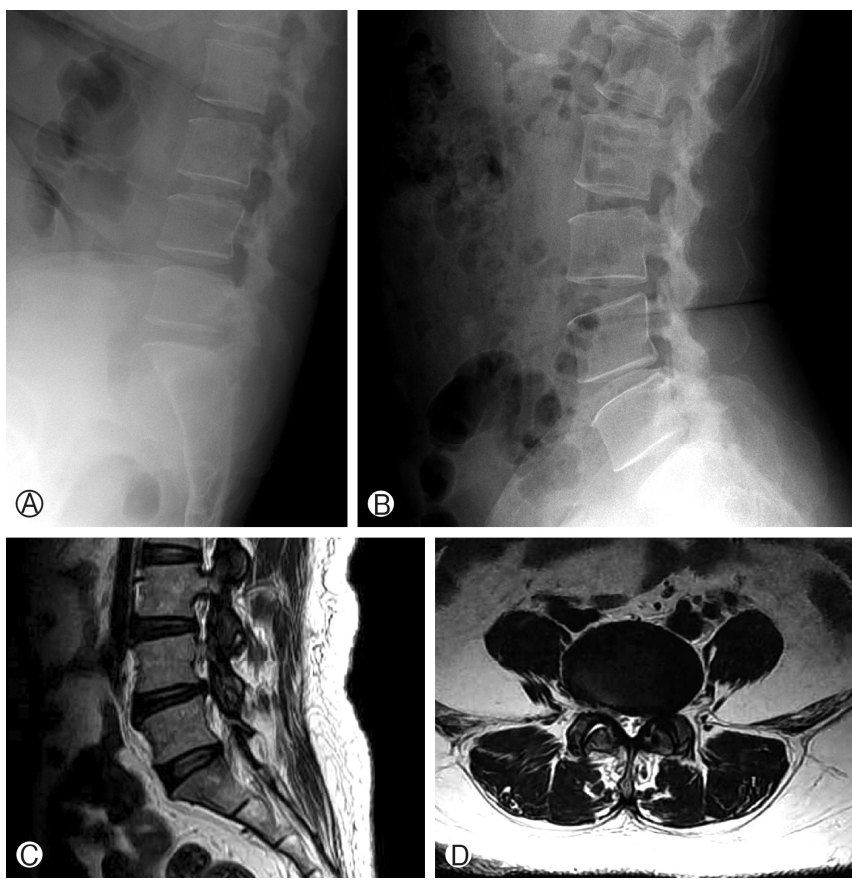

Fig. 1. Preoperative simple flexion and extension views $(\mathrm{A}, \mathrm{B})$ and T2-weighted magnetic resonance images $(C, D)$ show disc herniation at the L4-5 level without instability.
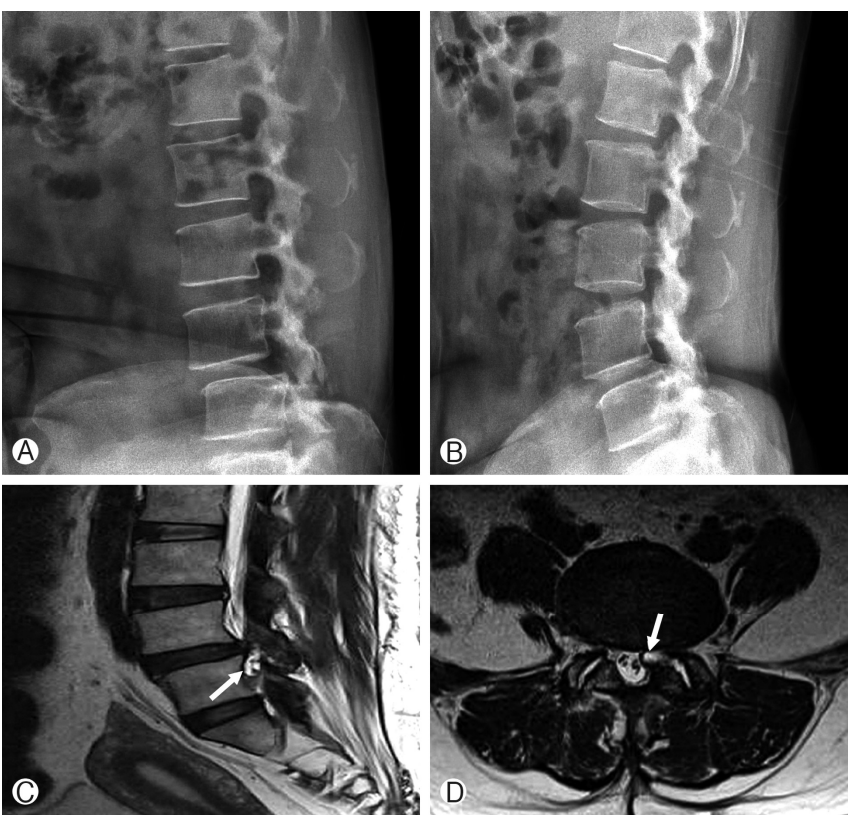

Fig. 2. At 6 months after microscopic discectomy, simple flexion and extension views (A, B) and T2-weighted magnetic resonance images $(C, D)$ revealed instability at the L4-5 level and a hypointense cystic mass (arrows) compressing the L5 root and the dural sac.

cysts ${ }^{5}$. In particular, synovial cysts are believed to develop from degenerative joint disease and to represent herniations of joint synovium; generally, they contain clear, serous fluid. Usually,

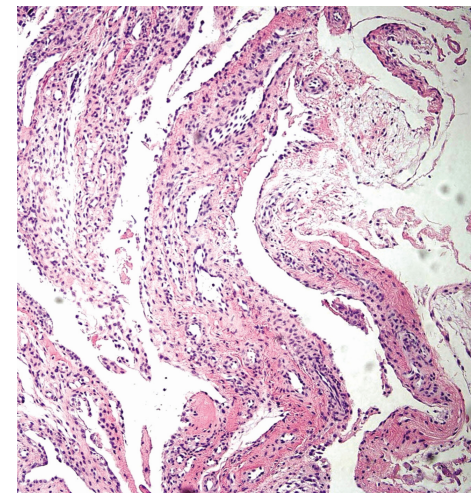

Fig. 3. Histological appearance of the hemorrhagic synovial cyst showing fibroconnective tissue and hemosiderin microdeposit $(\mathrm{H} \& \mathrm{E}, \times 100)$. a lumbar juxtafacet cyst remains asymptomatic for years until it gradually reaches a size capable of causing root radiculopathy or myelopathy. Rapid expansion of a synovial cyst causing severe symptoms is rare ${ }^{5)}$. However, spontaneous bleeding into a cyst could uncommonly exacerbate symptoms. Trauma, manipulative therapy, and anticoagulation therapy have been reported to precipitate hemorrhage on several occasions ${ }^{2,3,7}$.

The pathogenesis of intracystic bleeding has not been elucidated, but the formation of vascular neoendothelium has been observed in synovial cysts, and synovium itself is a vascular rich tissue. Neovascularization might be due to the production and release of angiogenic factors into a cyst under inflammatory circumstances. In fact, rupture of these fragile newly formed vessels results in acute bleeding even in the absence of a significant traumatic event ${ }^{6,10)}$. In our patient, microscopic discectomy following bilateral laminotomy might have caused postoperative spinal instability. Furthermore, ligamentum flavum might have been removed during decompression surgery, and consequent weakening of the medial portion of the facet joint may have allowed the joint capsule to protrude into the spinal canal. In addition, mechanical stress, such as, segmental spinal instability at the involved vertebral level, might aggravate joint capsule protrusion. Moreover, a high level of cyst vascularization could cause hemorrhage despite micromotion or mild spinal instability. Accordingly, synovial cyst hemorrhage may occur despite the absence of evident traumatic event or coagulopathy". MRI is considered a good diagnostic modality, although in case of bleeding, MR images vary and are dependent on the biochemical evolution of the hematoma. As a hematoma ages, hemoglobin passes through several forms from oxyhemoglobin and methemoglobin prior to red cell lysis and its breakdown into ferritin and hemosiderin. We report a case in which hemorrhage into a L4 -5 facet synovial cyst caused by spinal instability after microscopic discectomy in the absence of any trauma or coagulopathy caused radiculopathy. Surgical excision with decompression is the primary treatment for symptomatic lumbar hemorrhagic synovial cysts.

\section{CONCLUSION}

Although rare, a hemorrhagic lumbar facet cyst should be considered an uncommon complication after microscopic discectomy 
following bilateral laminotomy. Surgical removal is the treatment of choice for hemorrhagic lumbar facet cysts.

\section{CONFLICT OF INTEREST}

No potential conflict of interest relevant to this article was reported.

\section{ACKNOWLEDGMENTS}

This study was supported by research funds from Chosun University Hospital 2017.

\section{REFERENCES}

1. Cho SI, Lee JH, Chough CK: Postlaminectomy bilateral lumbar intraspinal synovial cysts. Korean J Spine 13:157-159, 2016

2. Eck JC, Triantafyllou SJ: Hemorrhagic lumbar synovial facet cyst secondary to anticoagulation therapy. Spine J 5:451-453, 2005

3. Nourbakhsh A, Garges KJ: Lumbar synovial joint hematoma in a patient on anticoagulation treatment. Spine (Phila Pa 1976) 32:
E300-302, 2007

4. Park HS, Sim HB, Kwon SC, Park JB: Hemorrhagic lumbar synovial cyst. J Korean Neurosurg Soc 52:567-569, 2012

5. Radatz M, Jakubowski J, Cooper J, Powell T: Synovial cysts of the lumbar spine: a review. Br J Neurosurg 11:520-524, 1997

6. Ramieri A, Domenicucci M, Seferi A, Paolini S, Petrozza V, Delfini R: Lumbar hemorrhagic synovial cysts: diagnosis, pathogenesis, and treatment. Report of 3 cases. Surg Neurol 65:385-390, 2006

7. Tatter SB, Cosgrove GR: Hemorrhage into a lumbar synovial cyst causing an acute cauda equina syndrome. Case report. J Neurosurg 81:449-452, 1994

8. Wait SD, Jones FD, Lonser RR, Lee KS: Symptomatic epidural hematoma caused by lumbar synovial cyst rupture: report of two cases and review of the literature. Neurosurgery 56:E1157, 2005

9. Xu R, Solakoglu C, Maleki Z, McGirt MJ, Gokaslan ZL, Bydon A: Hemorrhagic synovial cyst: the possible role of initial trauma and subsequent microtrauma in its pathogenesis: case report. Neurosurgery 68:E858-865, 2011

10. Yarde WL, Arnold PM, Kepes JJ, O’Boynick PL, Wilkinson SB, Batnitzky S: Synovial cysts of the lumbar spine: diagnosis, surgical management, and pathogenesis. Report of eight cases. Surg Neurol 43:459-464, 1995 